\title{
Article \\ Effect of Batchelor Flow on Polymorphic Crystallization in a Rotating Disk Crystallizer
}

\author{
Zun-Hua Li, Jinsoo Kim and Woo-Sik Kim *
}

\author{
Functional Crystallization Center, Department of Chemical Engineering (Integrated Engineering Program), \\ Kyung Hee University, Seocheon-Dong 1, Giheung-gu, Yongin-si 446-701, Korea; zhli@khu.ac.kr (Z.-H.L.); \\ jkim21@khu.ac.kr (J.K.) \\ * Correspondence: wskim@khu.ac.kr; Tel.: +82-31-201-2970; Fax: +82-31-273-2971
}

check for updates

Citation: Li, Z.-H.; Kim, J.; Kim, W.-S. Effect of Batchelor Flow on Polymorphic Crystallization in a Rotating Disk Crystallizer. Crystals 2021, 11, 701. https://doi.org/ $10.3390 /$ cryst11060701

Academic Editors: Hiroshi Ooshima, Joop H. ter Horst and Koichi Igarashi

Received: 11 April 2021

Accepted: 15 June 2021

Published: 18 June 2021

Publisher's Note: MDPI stays neutral with regard to jurisdictional claims in published maps and institutional affiliations.

Copyright: (c) 2021 by the authors. Licensee MDPI, Basel, Switzerland. This article is an open access article distributed under the terms and conditions of the Creative Commons Attribution (CC BY) license (https:// creativecommons.org/licenses/by/ $4.0 /)$.

\begin{abstract}
In this work, the influence of Batchelor flow on the polymorphic crystallization in a rotating disk (RD) crystallizer was investigated. By regulating crystallization parameters, i.e., the rotation speed, cooling rate, and ethanol fraction, we found that a higher fraction of L-histidine stable Form-A at the induction time and a faster rate of phase transformation could be obtained in the RD crystallizer as compared to previous results in a mixing tank crystallizer. Based on these results, we concluded that the polymorphic crystallization in the RD crystallizer was more effective due to Batchelor flow fluid motion.
\end{abstract}

Keywords: Batchelor flow; rotating disk crystallizer; selective nucleation; phase transformation

\section{Introduction}

Currently, polymorphism is of great interest to the pharmaceutical industry due to the distinct properties of polymorphs, including their bioavailability, solubility, and stability [1-3]. Therefore, polymorphic crystallization plays a critical role in harvesting desired polymorphs for pharmaceutical applications. Previous studies on polymorphism in the crystallization process have demonstrated that experimental conditions, such as the rotation speed, supersaturation, solvent, cooling rate, ultrasound, and additives (seeding), are influential parameters affecting the resultant polymorphs in the process of polymorphic crystallization [4-9]. Hydrodynamics frequently plays a key role in these parameters during polymorphic crystallization. The stable form of carbamazepine crystals nucleated under the agitated state. However, metastable-form crystals were merely generated under the quiescent state [10]. Stirring can not only improve the nucleation of the stable phase of L-glutamic acid but can also enhance the phase transformation rate [11,12]. Furthermore, it was also demonstrated that the hydrodynamics pattern and stirring speed can affect the polymorphic nucleation [13].

We have previously reported the efficacy of the Batchelor flow in co-crystallization [14] and spherical agglomeration [15] and that of the Taylor flow in the reaction [16-18], antisolvent [19,20], and cooling crystallization [21-25], which, in turn, concern the stoichiometrically diverse co-crystals, crystal agglomeration, polymorphic nucleation, phase transformations, crystal size distributions, and crystal shapes. Hence, this work intends to study the effect of periodic Batchelor flow on the polymorphic crystallization in a rotating disk (RD) crystallizer. The Batchelor flow fluid motion was generated in fluid [26], which consisted of a Bödewadt layer and a von Kármán layer [27,28]; the Batchelor flow can be classified into four types of flow regimes [29-31]. In this study, the RD crystallizer exhibited laminar or turbulent Batchelor flow regimes, which were highly dependent on the rotation speed. This type of reactor possesses good scalability for industrial applications, such as its high mass transfer. For example, Visscher et al. demonstrated that the mass transfer rate of liquid-liquid in an RD reactor was ten times higher than that in a packed column and art microchannel [32]. Moreover, the liquid-solid mass transfer rate in the RD reactor 
was much higher than that in a packed bed reactor [33]. According to the above literature reports, it is logical to speculate that the application of a stator-rotor cavity reactor will also greatly improve the crystallization efficiency, such as the phase transformation and nucleation.

Herein, we employed an RD crystallizer instead of a traditional crystallizer to investigate the effect of Batchelor flow on the polymorphic crystallization at varying rotation speeds. In addition, the role of crystallization parameters, such as the cooling rate and ethanol fraction, was also investigated to comprehensively analyze the effect of the RD crystallizer performance.

\section{Materials and Methods}

As shown in Figure 1, the RD crystallizer was equipped with thermal jackets on the rotor and stator. In addition, a heating and cooling circulator was used for temperature control, and a thermocouple was used for temperature monitoring. The reaction space of the RD crystallizer between the rotor and stator was around $420 \mathrm{~cm}^{3}$. L-histidine solid (Sigma-Aldrich, Saint Louis, MO, USA, stable Form-A, purity $\geq 99 \%$ ) was dissolved in a solvent at a temperature that was $5{ }^{\circ} \mathrm{C}$ higher than the saturation temperature to prepare the feed solution. The ethanol fraction was adjusted from 0 to 30, 40, and $50 v / v \%$ for the four corresponding samples. In addition, the initial concentration of the feed solution was set to 7.00, 2.00, 1.50, and $0.75 \mathrm{~g} / 100 \mathrm{~g}$ solvent, respectively. Ethanol was obtained from Samchun Chem. (purity $\geq 99.5 \%$, Seoul, Korea), and the water was membrane-purified (Applied Membranes Inc., Vista, CA, USA). The prepared feed solution was then pumped into the preheated RD crystallizer by the peristaltic pump. The rotor was rotated by the motor for half an hour to stabilize the system and to generate Batchelor flow fluid motion. The flow pattern in the RD crystallizer followed laminar Batchelor flow or turbulent Batchelor flow depending on the rotation speed. However, both flow patterns exhibited periodic fluid motion. Furthermore, the rotation speed was changed from 300 to 500, 700, 1000, and $1500 \mathrm{rpm}$. Moreover, the cooling rate was varied from 10 to 30,150 , and $360^{\circ} \mathrm{C} / \mathrm{h}$. The initial and final setting temperatures were 50 and $10{ }^{\circ} \mathrm{C}$, respectively. After reaching an extremely fast cooling rate of $360^{\circ} \mathrm{C} / \mathrm{h}$, the feed solution in the RD crystallizer was first heated to the initial setting temperature of $50^{\circ} \mathrm{C}$ by one heating and cooling circulator, after which the RD crystallizer was quickly shifted to another heating and cooling circulator, which cooled the solution to $10^{\circ} \mathrm{C}$. When the feed solution reached $10^{\circ} \mathrm{C}$, the cooling rate was calculated by evaluating the cooling time. Crystallization was continued for $500 \mathrm{~min}$ after the temperature in the RD crystallizer reached the final setting temperature.

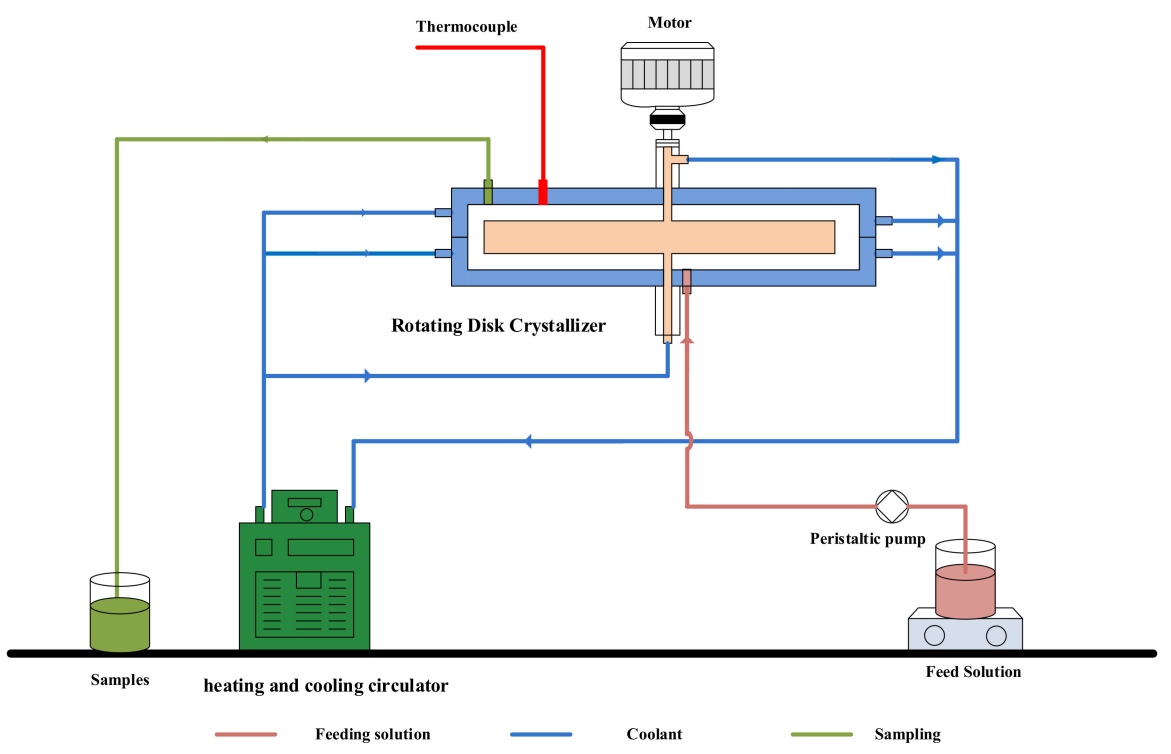

Figure 1. Schematic diagram of a rotating disk (RD) crystallizer for cooling crystallization. 
In order to monitor the entire crystallization process, the crystal samples suspended in the solution were intermittently collected. The suspension was filtered, and then the obtained powder was dried for $12 \mathrm{~h}$ in an oven at $60^{\circ} \mathrm{C}$. In the process of sampling, the prepared feed solution was simultaneously refilled into the RD crystallizer to maintain the experimental consistency of the Batchelor flow fluid motion in the crystallization process. All collected crystal samples were characterized by powder X-ray diffraction (PXRD; Bruker, D8 Advance, Karlsruhe, Germany) and Fourier-transform-Raman-spectroscopy (FT-Raman; Renishaw, Gloucestershire, UK). The polymorph calibration of the L-histidine crystals followed a previously established protocol [25].

\section{Result and Discussion}

\subsection{Effect of Rotation Speed}

The effect of rotation speed on polymorphic crystallization was studied by changing the rotation speed from 300 to $1500 \mathrm{rpm}$ in the RD crystallizer, and the results are shown in Figure 2. In order to ensure the repeatability of the experiment, each experiment was performed in triplicate. The induction time $\left(t_{I}\right)$ at different rotation speeds is indicated by the different colored vertical dotted lines, and the fraction of L-histidine stable Form$A$ at the induction time $\left(\mathrm{A}_{\mathrm{I}} \%\right)$ at different rotation speeds is indicated by the different colored horizontal dotted lines. It was demonstrated that the $t_{I}$ decreased from 112 (black vertical dotted line) to $52 \mathrm{~min}$ (pink vertical dotted line), while the $\mathrm{A}_{\mathrm{I}} \%$ increased from approximately 35\% (black horizontal dotted line) to $76 \%$ (pink horizontal dotted line) when the rotation speed increased from 300 to $1500 \mathrm{rpm}$. After the induction, the crystallization process was followed by the phase transformation, and the fraction of L-histidine stable Form-A was increased at each rotation speed following the crystallization time. Finally, the fraction of L-histidine stable Form-A was increased from about $54 \%$ to $100 \%$ as the rotation speed increased from 300 to $1500 \mathrm{rpm}$ when the crystallization time was $500 \mathrm{~min}$. It should be noted that the fraction of L-histidine stable Form-A reached $100 \%$ only when the rotation speed was higher than $1000 \mathrm{rpm}$. This indicated that samples obtained from those two higher rotation speeds were the pure stable Form-A of L-histidine. Interestingly, at the low rotation speeds, including 300,500, and $700 \mathrm{rpm}$, the fraction of L-histidine stable Form-A was still increasing slightly when the crystallization time approached 500 min; therefore, it could be speculated that the fraction of L-histidine stable Form-A at 300, 500, and $700 \mathrm{rpm}$ can also reach $100 \%$ after an extremely long crystallization time.

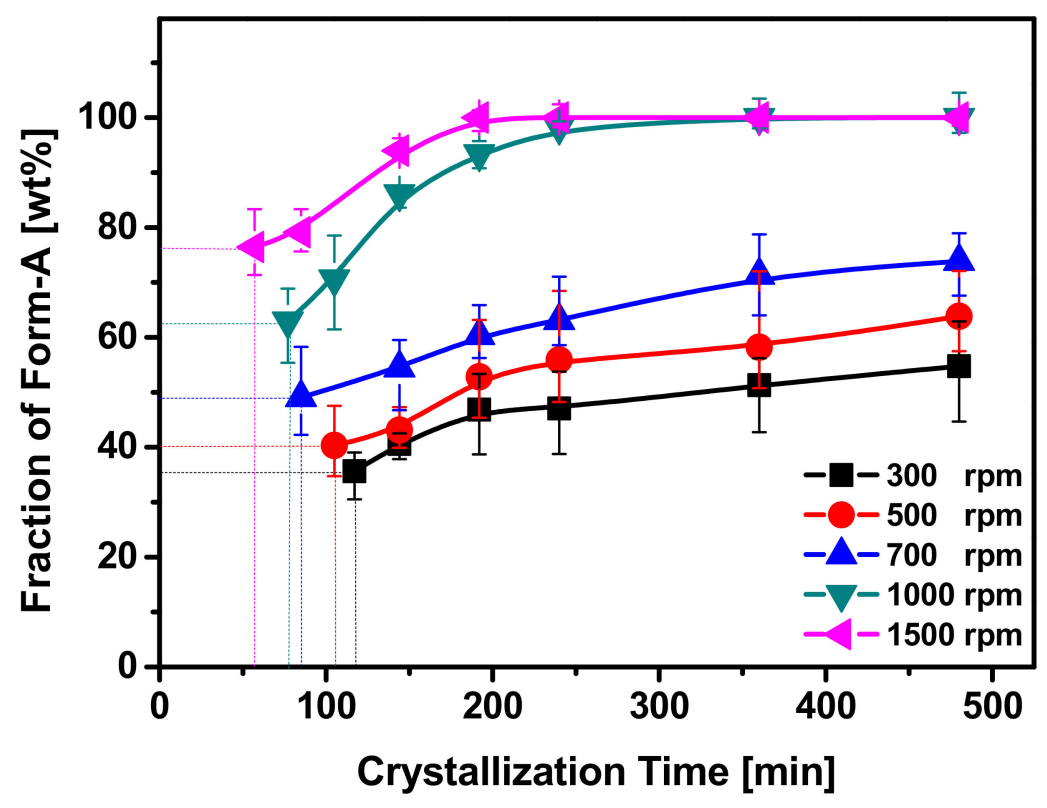

Figure 2. Fraction of the Form-A profile at different rotation speeds. The cooling rate was $10{ }^{\circ} \mathrm{C} / \mathrm{h}$, the ethanol fraction was $30 \%$, and the induction time $\left(t_{\mathrm{I}}\right)$ is indicated by the dotted line. 
Raman spectroscopy was performed on the L-histidine polymorphic samples to determine the L-histidine stable Form-A fraction. As shown in Figure 3a, the absorption peak that appeared at $215-245 \mathrm{~cm}^{-1}$ can be defined as the characteristic peak of Form-A, and the polymorphic fraction of Form-A was proportional to the peak area ratio. Therefore, the fraction of Form-A could be obtained by the peak area ratio shown in Figure 3b, and by following the protocol previously reported by Park and Kim [25]. Accordingly, the weight fraction of the L-histidine stable Form-A quickly increased from 76\% (57 min) to 100\% (192 min) within $135 \mathrm{~min}$ at $1500 \mathrm{rpm}$. To further confirm the formation of the L-histidine stable Form-A, the PXRD results were used to analyze the samples obtained at different times, as shown in Figure 3c. According to Park and Kim [25], the diffraction peak at $17.75^{\circ}$ was defined as the feature peak of L-histidine stable Form-A, and the diffraction peak at $17.28^{\circ}$ was defined as the feature peak of L-histidine metastable Form-B. Therefore, as shown in Figure 3c, when the rotation speed was $1500 \mathrm{rpm}$, the feature peak intensity of L-histidine stable Form-A at $17.75^{\circ}$ quickly increased as the crystallization time increased from 57 to $192 \mathrm{~min}$. In comparison, the feature peak intensity of L-histidine metastable Form-B at $17.28^{\circ}$ quickly decreased and finally disappeared. The results demonstrated that the sample obtained at 192 min was pure L-histidine stable Form-A.

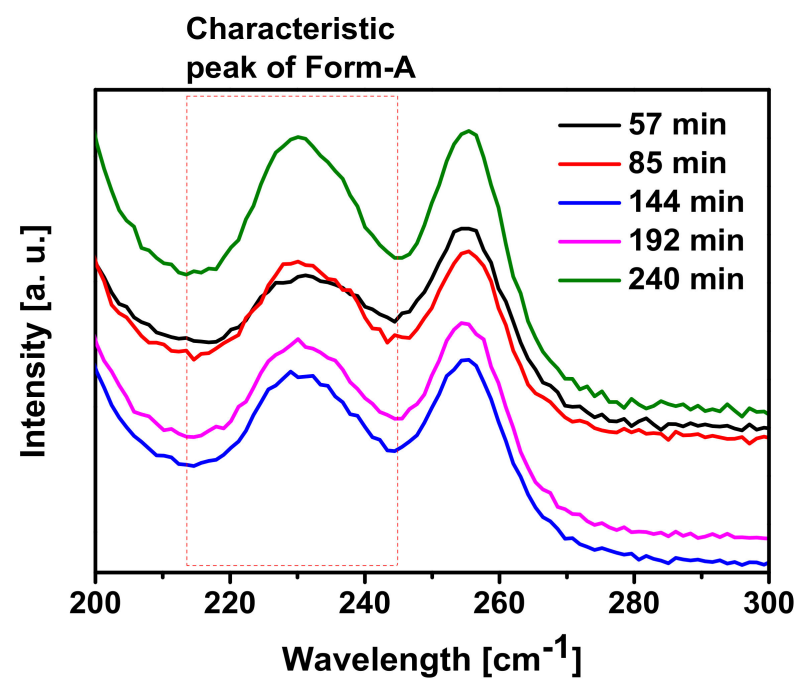

(a)

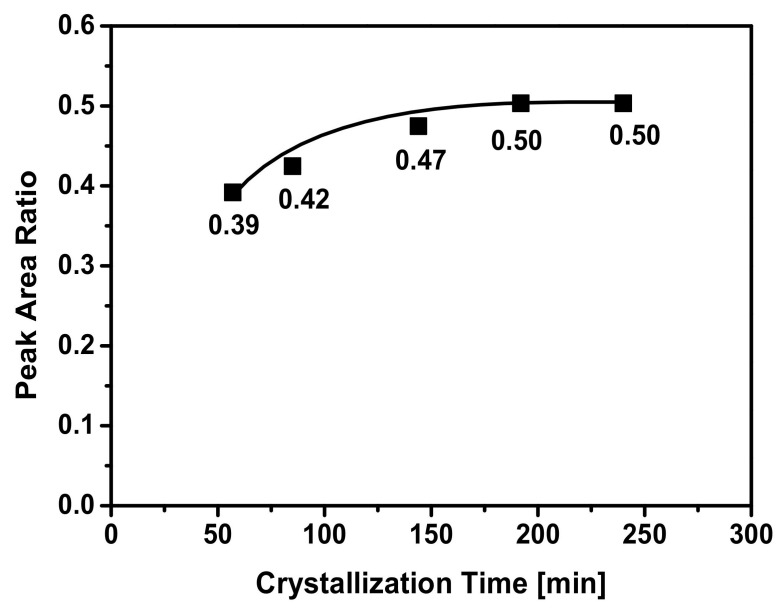

(b)

Figure 3. Cont. 


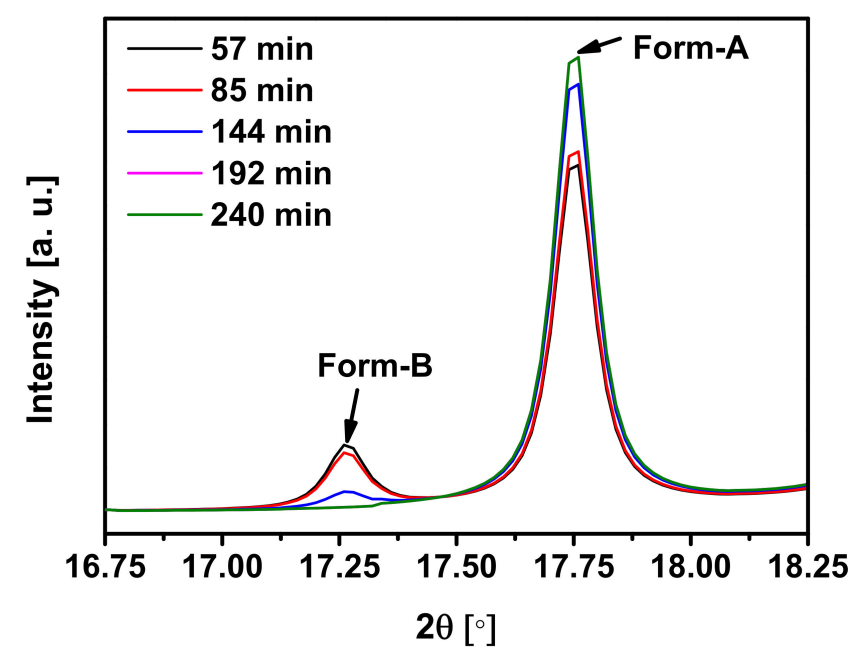

(c)

Figure 3. Characterization of the samples obtained during cooling crystallization at a rotation speed of $1500 \mathrm{rpm}$. (a) Raman spectroscopy, (b) peak area ratio of the samples obtained at different crystallization times, and (c) powder X-ray diffraction (PXRD) pattern. The cooling rate was $10^{\circ} \mathrm{C} / \mathrm{h}$ and the ethanol fraction was 30\%. Peak area ratio $=\left[\left(\right.\right.$ peak area of $\left.\left.215-245 \mathrm{~cm}^{-1}\right)\right] /[($ peak area of $\left.215-245 \mathrm{~cm}^{-1}\right)+\left(\right.$ peak area of $\left.\left.245-270 \mathrm{~cm}^{-1}\right)\right]$.

As indicated in Figure $4 \mathrm{a}$, the $\mathrm{A}_{\mathrm{I}} \%$ increased linearly from $35 \%$ to $76 \%$, implying that higher rotation speeds were more efficient for the nucleation of L-histidine stable Form-A because a higher rotation speed provided a higher energy dissipation rate to enhance L-histidine stable Form-A nucleation. Moreover, the effect of rotation speed on the polymorphic nucleation was distinctly confirmed by analyzing the $t_{I}$ and induction temperature $\left(T_{I}\right)$. Figure $4 b$ shows the results following a linear $t_{I}$ decrease from 112 to 52 min and a $T_{I}$ increase from 31 to $41{ }^{\circ} \mathrm{C}$. The higher rotation speed was more efficient during the shorter $t_{I}$ and at higher $\mathrm{T}_{\mathrm{I}}$. Therefore, it was implied that a higher rotation speed induced nucleation at a lower supersaturation level. Similarly, this lower supersaturation level may facilitate L-histidine stable Form-A nucleation, resulting in a high $\mathrm{A}_{I} \%$. In addition, as compared to the same experiments with an MT crystallizer, the $t_{I}$ was approximately 30 min earlier and the $\mathrm{T}_{\mathrm{I}}$ was approximately $5{ }^{\circ} \mathrm{C}$ higher in Batchelor flow [25]. As shown in Figure 2, $100 \%$ L-histidine stable Form-A was obtained at $192 \mathrm{~min}$ in the RD crystallizer at $1500 \mathrm{rpm}$, while a longer time $(88.5 \mathrm{~h}$ ) was required to achieve $100 \%$ L-histidine stable Form-A in the MT crystallizer [25].

As demonstrated in Figure 5, the rate of phase transformation was proportional to the rotation speed. The phase transformation rate was increased from 3.15 to $6.25 \mathrm{wt} \% / \mathrm{h}$. Normally, the phase transformation is directly related to the mass transfer. Therefore, the rate of phase transformation increased because of the acceleration of mass transfer caused by the increase in rotation speed. This result also demonstrated that mass transfer relies on rotation speed, which was confirmed by previous studies [20,22,25]. 


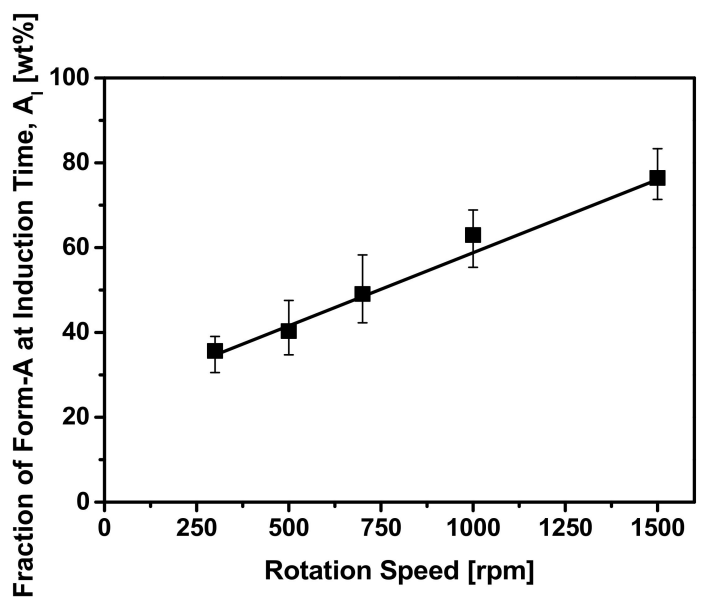

(a)

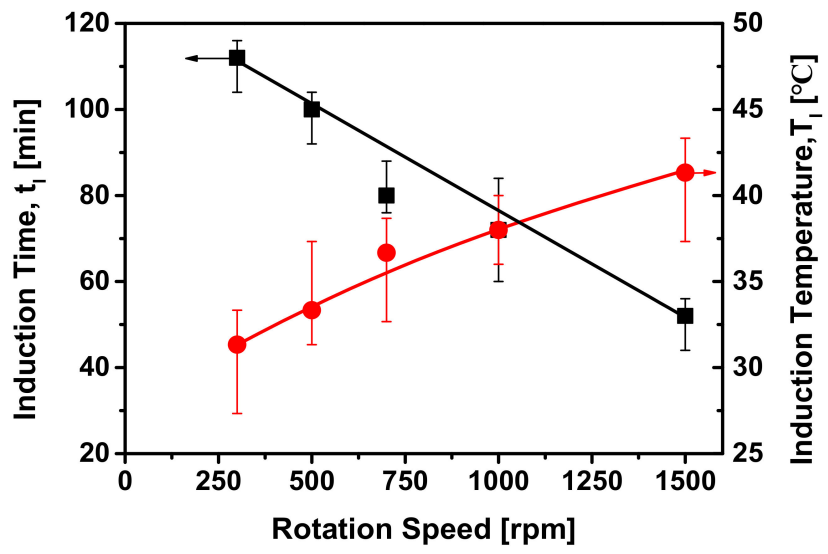

(b)

Figure 4. Effect of rotation speed on polymorphic nucleation: (a) $A_{I} \%$ and (b) $t_{I}$ and $T_{I}$. The cooling rate was $10^{\circ} \mathrm{C} / \mathrm{h}$ and the ethanol fraction was $30 \%$.

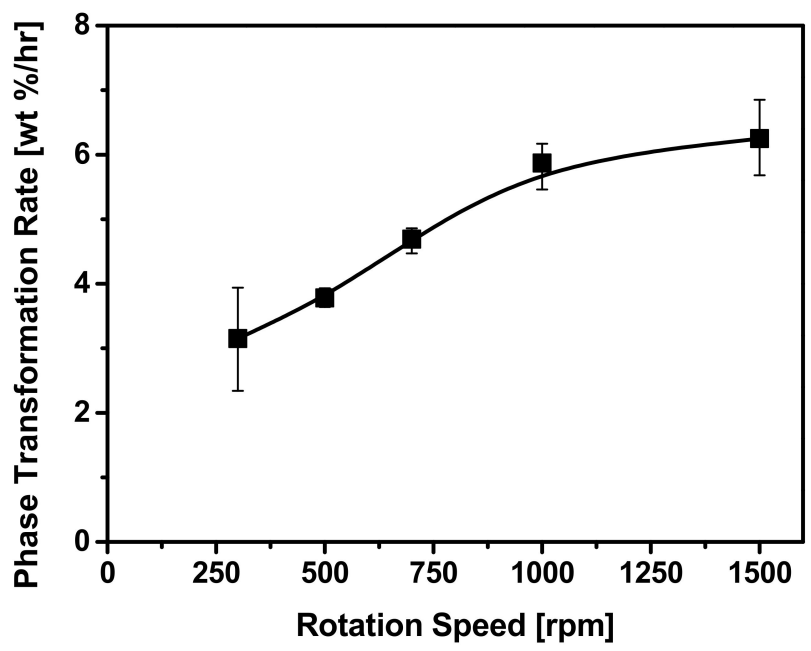

Figure 5. Effect of rotation speed on the rate of phase transformation. The cooling rate was $10^{\circ} \mathrm{C} / \mathrm{h}$ and the ethanol fraction was $30 \%$. 


\subsection{Effect of Cooling Rate}

The effect of cooling rate on the polymorphic crystallization of L-histidine was studied by changing the cooling rate from 10 to $360{ }^{\circ} \mathrm{C} / \mathrm{h}$. As shown in Figure $6 \mathrm{a}$, the $\mathrm{A}_{\mathrm{I}} \%$ decreased from $40 \%$ to $20 \%$ as the cooling rate increased from 10 to $30{ }^{\circ} \mathrm{C} / \mathrm{h}$, which indicated that a slower cooling rate was more efficient for the nucleation of L-histidine stable Form-A. However, it should be noted that the $\mathrm{A}_{I} \%$ was just shown a small change when the cooling rate was great than $30{ }^{\circ} \mathrm{C} / \mathrm{h}$, such as the $17 \%$ and $16 \%$ of $\mathrm{A}_{\mathrm{I}} \%$ was obtained at the cooling rate of $150{ }^{\circ} \mathrm{C} / \mathrm{h}$ and $360^{\circ} \mathrm{C} / \mathrm{h}$, respectively. It implied that a higher cooling rate has a small effect on enhancing the nucleation of L-histidine stable Form-A. Generally, in the pharmaceutical industry, a very high cooling rate, such as 150 or $360^{\circ} \mathrm{C} / \mathrm{h}$, is difficult to achieve. Therefore, a slow cooling rate is a good choice for cooling polymorphic crystallization of the stable form. Moreover, the effect of cooling rate on polymorphic nucleation can be confirmed by measuring the $t_{I}$ and $T_{I}$ of nucleation. As shown in Figure $6 b$, the $t_{I}$ dramatically decreased from 90 to 3.6 min and the $T_{I}$ linearly decreased from 40 to $30^{\circ} \mathrm{C}$ as the cooling rate increased from 10 to $360^{\circ} \mathrm{C} / \mathrm{h}$. These results indicate that both the $t_{I}$ and $T_{I}$ were reduced as the cooling rate increased because the supersaturation level increased with the cooling rate. Therefore, a lower $A_{I} \%$ was induced by the higher initial supersaturation level.

Moreover, as indicated in Figure 7, the rate of phase transformation was highly dependent on the cooling rate. The phase transformation rate dramatically decreased from 3.83 to $1.05 \mathrm{wt} \% / \mathrm{h}$ as the cooling rate increased from 10 to $30^{\circ} \mathrm{C} / \mathrm{h}$. Moreover, it should be noted that the phase transformation rate only had a small change when the cooling rate was greater than $30^{\circ} \mathrm{C} / \mathrm{h}$; for example, phase transformation rates of 0.60 and $0.44 \mathrm{wt} \% / \mathrm{h}$ were achieved at the cooling rates of 150 and $360{ }^{\circ} \mathrm{C} / \mathrm{h}$, respectively. It implied that a higher cooling rate showed a smaller effect on the phase transformation rate of L-histidine.

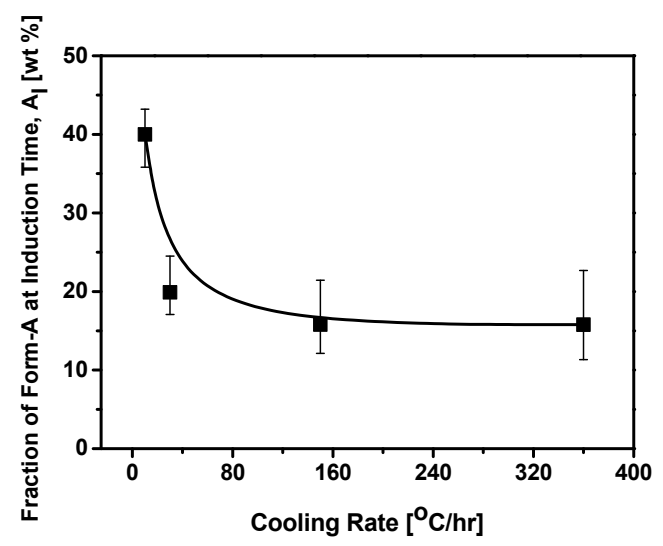

(a)

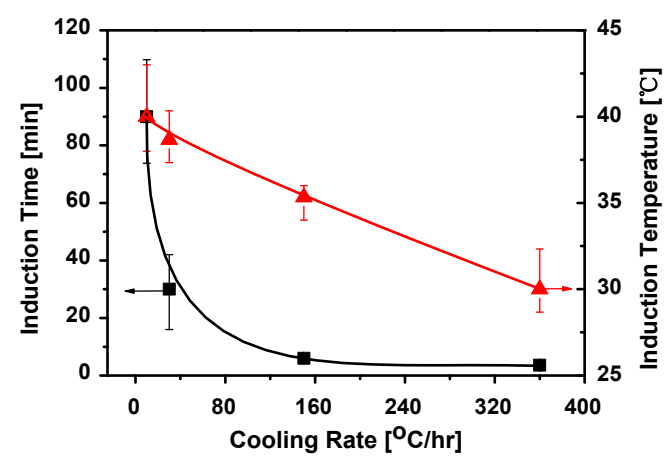

(b)

Figure 6. Effect of cooling rate on polymorphic nucleation: (a) $\mathrm{A}_{\mathrm{I}} \%$, and (b) $\mathrm{t}_{\mathrm{I}}$ and $\mathrm{T}_{\mathrm{I}}$. The rotation speed was $500 \mathrm{rpm}$ and the ethanol fraction was $30 \%$. 


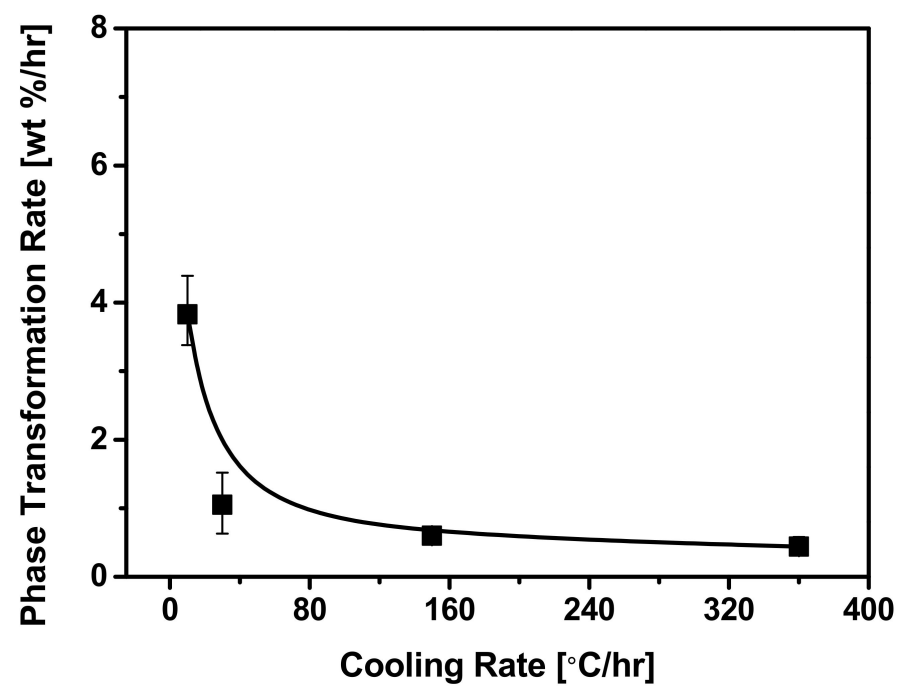

Figure 7. Effect of cooling rate on the phase transformation rate. The rotation speed was $500 \mathrm{rpm}$ and the ethanol fraction was $30 \%$.

\subsection{Effect of Ethanol Fraction}

The influence of ethanol fraction on polymorphic crystallization was studied by changing the fraction of ethanol from 0 to $50 \mathrm{vol} \%$ in the RD crystallizer, and the results are shown in Figure 8. The $t_{I}$ at different ethanol fractions is indicated by the different colored vertical dotted lines, and the $\mathrm{A}_{\mathrm{I}} \%$ at different ethanol fractions is indicated by the different colored horizontal dotted lines. It is indicated that the $t_{I}$ decreased from 108 (green vertical dotted line) to $48 \mathrm{~min}$ (black vertical dotted line), and the $\mathrm{A}_{\mathrm{I}} \%$ increased from $17 \%$ (green horizontal dotted line) to $71 \%$ (black horizontal dotted line) when the ethanol fraction was decreased from 50 to $0 \mathrm{vol} \%$. With the increasing crystallization time, the fraction of L-histidine stable Form-A was increased at each ethanol fraction. Until the end of the experiment after $500 \mathrm{~min}$, the fraction of L-histidine stable Form-A decreased from $100 \%$ to $28 \%$ as the ethanol fraction increased from 0 to $50 \mathrm{vol} \%$. It should be noted that when the ethanol fraction was $0 \mathrm{vol} \%$, the fraction of L-histidine stable Form-A was $100 \%$, which showed that the sample was the pure stable Form-A of L-histidine at an ethanol fraction of $0 \mathrm{vol} \%$. Interestingly, the fraction of L-histidine stable Form-A obtained at ethanol fractions of 30,40, and $50 \mathrm{vol} \%$ still had a slight increase when the crystallization time approached $500 \mathrm{~min}$. Therefore, we also can speculate that the fraction of L-histidine stable Form-A at 30,40 , and $50 \mathrm{vol} \%$ also can reach $100 \%$ with an extremely long crystallization time.

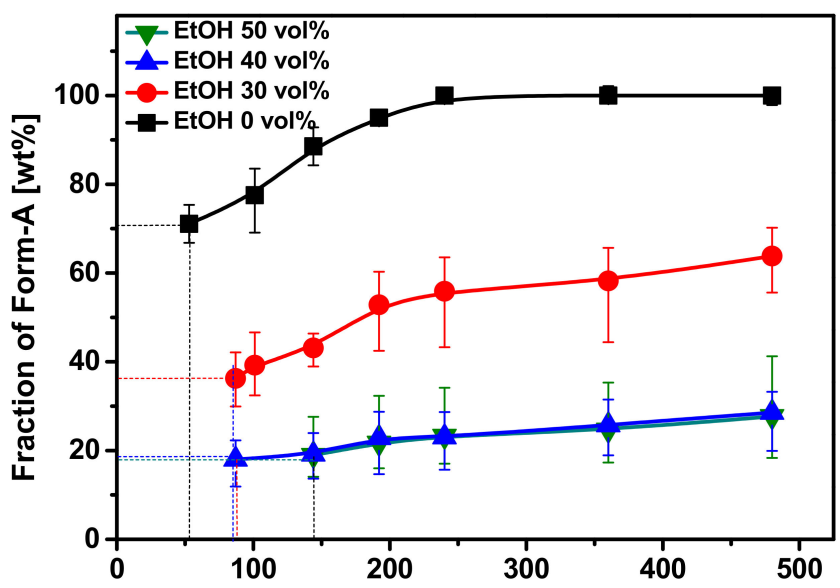

Figure 8. Fraction of the Form-A profile at different ethanol fractions. The rotation speed was $500 \mathrm{rpm}$ and the cooling rate was $10^{\circ} \mathrm{C} / \mathrm{h}$, and the induction time $\left(\mathrm{t}_{\mathrm{I}}\right)$ is indicated by the dotted line. 
The $\mathrm{A}_{\mathrm{I}} \%$ and the final fraction of L-histidine stable Form-A were dependent on the ethanol fraction. It can be seen from Figure $9 \mathrm{a}$ that the use of $0 \mathrm{vol} \%$ ethanol as the solvent produced an $\mathrm{A}_{\mathrm{I}} \%$ of approximately $71 \%$, which then rapidly increased to $100 \%$ after $240 \mathrm{~min}$ at $500 \mathrm{rpm}$. The $\mathrm{A}_{\mathrm{I}} \%$ increased from $17 \%$ to $71 \%$ as the ethanol fraction was decreased from 50 to $0 \mathrm{vol} \%$. Moreover, the $t_{I}$ increased from 48 to $108 \mathrm{~min}$ and the $\mathrm{T}_{\mathrm{I}}$ decreased from 42 to $32{ }^{\circ} \mathrm{C}$ as the ethanol fraction increased from 0 to $50 \mathrm{vol} \%$ (Figure $9 \mathrm{~b}$ ). In general, polymorphic crystallization is associated with the composition of the solvent because the solubility of the polymorphs is dependent on the mixed solvent. Therefore, the polymorph solubility of L-histidine was observed to be reduced as the ethanol fraction increased [25]. As a result, when the ethanol fraction increased, nucleation proceeded at a higher supersaturation level, thus producing a lower $\mathrm{A}_{\mathrm{I}} \%$. Moreover, the solubility difference is an actual driving force in the process of phase transformation, which dramatically increased when the ethanol fraction was decreased, leading to a fast phase transformation. Therefore, when the ethanol fraction was decreased, the solubility difference increased, resulting in a dramatic increase in the rate of phase transformation. As demonstrated in Figure 10, the rate of phase transformation increased from 1.47 to $8.13 \mathrm{wt} \% / \mathrm{h}$ as the ethanol fraction decreased from 50 to $0 \mathrm{vol} \%$.

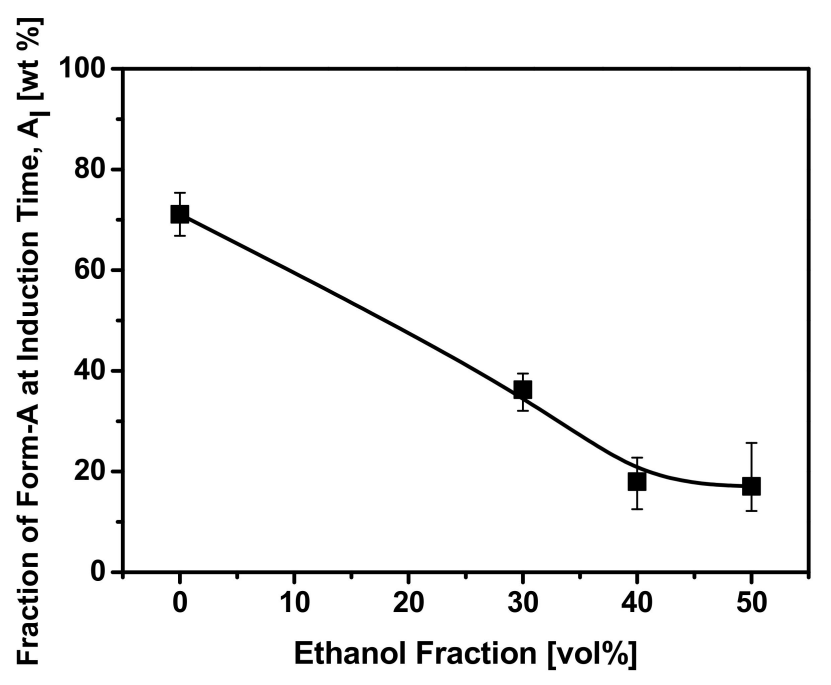

(a)

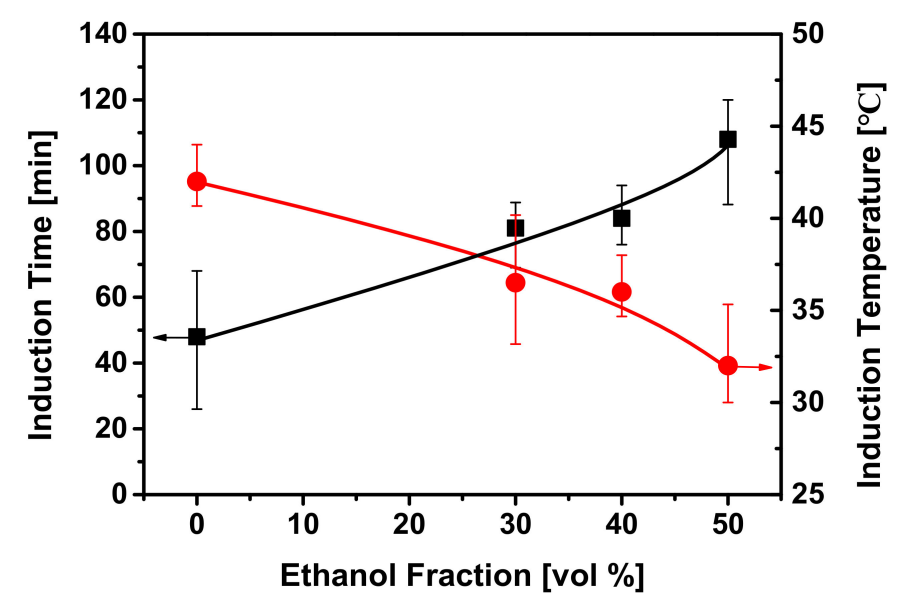

(b)

Figure 9. Effect of ethanol fraction on polymorphic nucleation: (a) $A_{I} \%$ and $(\mathbf{b}) t_{I}$ and $T_{I}$. The rotation speed was $500 \mathrm{rpm}$ and the cooling rate was $10^{\circ} \mathrm{C} / \mathrm{h}$. 


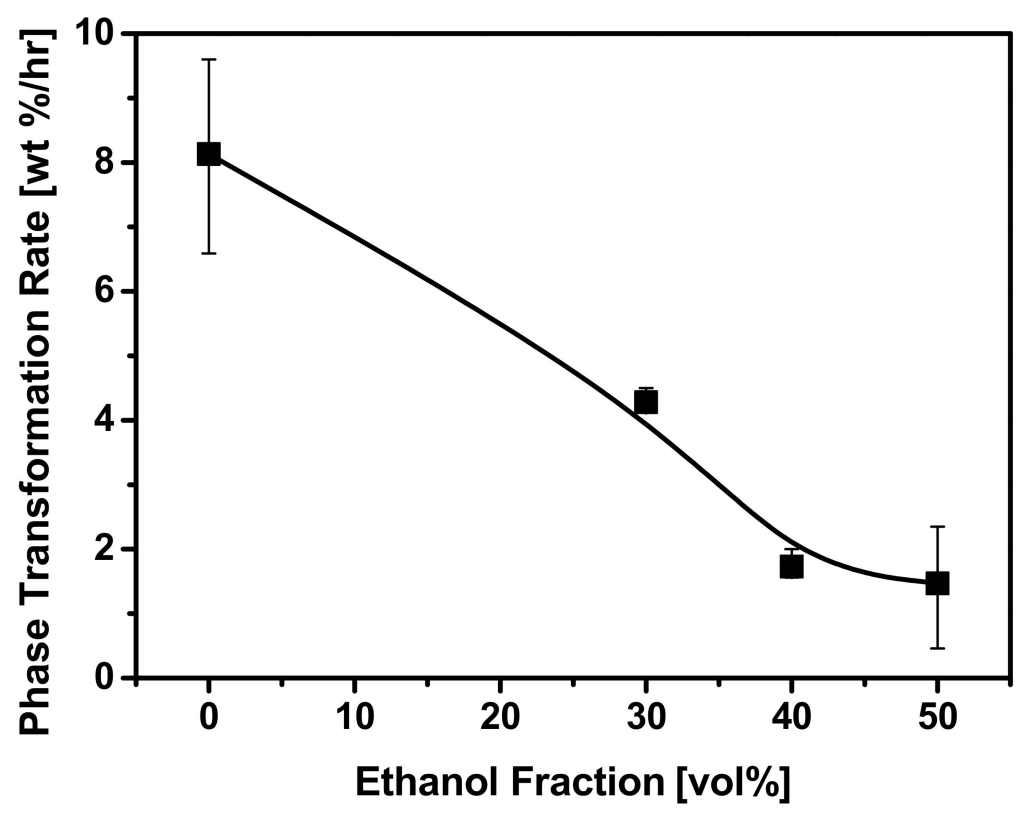

Figure 10. Effect of ethanol fraction on the phase transformation rate. The rotation speed was $500 \mathrm{rpm}$ and the cooling rate was $10^{\circ} \mathrm{C} / \mathrm{h}$.

\section{Conclusions}

The present study investigated the performance of an RD crystallizer in polymorphic crystallization of L-histidine by regulating the rotation speed, cooling rate, and ethanol fraction. The RD crystallizer dramatically facilitated the nucleation of stable Form-A due to the efficient Batchelor flow for mass transfer, and 100\% Form-A was obtained after only $192 \mathrm{~min}$ at $1500 \mathrm{rpm}$. In addition, the cooling rate and ethanol fraction were also linked to polymorphic crystallization. The $\mathrm{A}_{\mathrm{I}} \%$ and the rate of phase transformation decreased as the cooling rate increased because the supersaturation level also increased. In addition, the induction supersaturation level was significantly dependent upon the ethanol fraction. Therefore, a lower $\mathrm{A}_{\mathrm{I}} \%$ was observed at a higher ethanol fraction. Moreover, an increase in the ethanol fraction dramatically decreased the rate of phase transformation due to the small solubility difference. These results show that polymorphic crystallization was more effective because of the role of Batchelor flow in the RD crystallizer.

Author Contributions: Conceptualization, Z.-H.L. and W.-S.K.; writing-original draft preparation, Z.-H.L.; writing-review and editing, J.K. and W.-S.K.; supervision, W.-S.K. All authors have read and agreed to the published version of the manuscript.

Funding: This research was funded by the Engineering Research Center of Excellence Program of the National Research Foundation of Korea (NRF) (Grant NRF-2021R1A5A6002853).

Data Availability Statement: Not Applicable.

Acknowledgments: Zun-Hua Li was financially supported by the China Scholarship Council.

Conflicts of Interest: The authors declare no conflict of interest.

\section{References}

1. Grant, D.J.W. Polymorphism in Pharmaceutical Solids; Marcel Dekker: New York, NY, USA, 1999.

2. Yang, L.; Yin, Q.; Hou, B.; Wang, Y.; Bao, Y.; Wang, J.; Hao, H. Solubility and Thermodynamic Stability of the Enantiotropic Polymorphs of 2,3,5-Trimethyl-1,4-Diacetoxybenzene. Ind. Eng. Chem. Res. 2013, 52, 2477-2485. [CrossRef]

3. Chong, H.; Victor, Y.J.R.; Grant, D.J.W. Polymorphic Screening: Influence of Solvent on the Rate of Solvent-Mediated Polymorphic Transformation. J. Pharm. Sci. 2001, 90, 1878-1890.

4. Kitamura, M. Controlling Factor of Polymorphism in Crystallization Process. J. Cryst. Growth 2002, 237-239, 2205-2214. [CrossRef] 
5. Lo, E.; Mattas, E.; Wei, C.; Kacsur, D.; Chen, C.-K. Simultaneous API Particle Size Reduction and Polymorph Transformation Using High Shear. Org. Process Res. Dev. 2012, 16, 102-108. [CrossRef]

6. Mazzanti, G.; Guthrie, S.E.; Sirota, E.B.; Marangoni, A.G.; Idziak, S.H.J. Orientation and Phase Transitions of Fat Crystals under Shear. Cryst. Growth Des. 2003, 3, 721-725. [CrossRef]

7. Gracin, S.; Uusi-Penttilä, M.; Rasmuson, Å.C. Influence of Ultrasound on the Nucleation of Polymorphs of p-Aminobenzoic Acid. Cryst. Growth Des. 2005, 5, 1787-1794. [CrossRef]

8. Caridi, A.; Kulkarni, S.A.; Di Profio, G.; Curcio, E.; ter Horst, J.H. Template-Induced Nucleation of Isonicotinamide Polymorphs. Cryst. Growth Des. 2014, 14, 1135-1141. [CrossRef]

9. Dhanasekaran, P.; Srinivasan, K. Nucleation Control, Separation and Bulk Growth of Metastable $\alpha$-L-Glutamic Acid Single Crystals in the Presence of L-Tyrosine. J. Cryst. Growth 2013, 364, 23-29. [CrossRef]

10. Sypek, K.; Burns, I.S.; Florence, A.J.; Sefcik, J. In Situ Monitoring of Stirring Effects on Polymorphic Transformations during Cooling Crystallization of Carbamazepine. Cryst. Growth Des. 2012, 12, 4821-4828. [CrossRef]

11. Liang, K.; White, G.; Wilkinson, D.; Ford, L.J.; Roberts, K.J.; Wood, W.M.L. An Examination into the Effect of Stirrer Material and Agitation Rate on the Nucleation of L-Glutamic Acid Batch Crystallized from Supersaturated Aqueous Solutions. Cryst. Growth Des. 2004, 4, 1039-1044. [CrossRef]

12. Croker, D.; Hodnett, B.K. Mechanistic Features of Polymorphic Transformations: The Role of Surfaces. Cryst. Growth Des. 2010, 10, 2806-2816. [CrossRef]

13. Liu, J.; Svärd, M.; Rasmuson, Å.C. Influence of Agitation and Fluid Shear on Nucleation of m-Hydroxybenzoic Acid Polymorphs. Cryst. Growth Des. 2014, 14, 5521-5531. [CrossRef]

14. Li, Z.-H.; Yu, T.; Lee, T.; Kim, W.-S. Cocrystallization of Caffeine-Maleic Acid in a Batchelor Vortex Flow. Cryst. Growth Des. 2020, 20, 1618-1627. [CrossRef]

15. Sun, X.; Kim, J.; Kim, W.-S. Spherical agglomeration of nickel-manganese-cobalt hydroxide in turbulent Batchelor vortex flow. Chem. Eng. J. 2021, 421, 129924. [CrossRef]

16. Jung, W.; Hoon Kang, S.; Kim, K.; Kim, W.; Kyun Choi, C. Precipitation of Calcium Carbonate Particles by Gas-Liquid Reaction: Morphology and Size Distribution of Particles in Couette-Taylor and Stirred Tank Reactors. J. Cryst. Growth 2010, 312, 3331-3339. [CrossRef]

17. Jung, T.; Kim, W.-S.; Choi, C.K. Effect of Non-Stoichiometry of Calcium Carbonate Precipitation in a Couette-Taylor Reactor. Cryst. Growth Des. 2004, 4, 491-495. [CrossRef]

18. Mayra, Q.-P.; Kim, W.-S. Agglomeration of Ni-Rich Hydroxide in Reaction Crystallization: Effect of Taylor Vortex Dimension and Intensity. Cryst. Growth Des. 2015, 15, 1726-1734. [CrossRef]

19. Lee, S.; Lee, C.H.; Kim, W.-S. Anti-Solvent Crystallization of L-Threonine in Taylor Crystallizers and MSMPR Crystallizer: Effect of Hydrodynamic Fluid Motions on Crystal Size, Shape and Recovery. J. Cryst. Growth 2017, 469, 119-127. [CrossRef]

20. Nguyen, A.-T.; Kim, J.-M.; Chang, S.-M.; Kim, W.-S. Taylor Vortex Effect on Phase Transformation of Guanosine 5-Monophosphate in Drowning-Out Crystallization. Ind. Eng. Chem. Res. 2010, 49, 4865-4872. [CrossRef]

21. Wu, Z.; Kim, D.H.; Kim, W.-S. Batch Cooling Crystallization in Non-Isothermal Taylor Vortex Flow: Effective Method for Controlling Crystal Size Distribution. Cryst. Growth Des. 2017, 17, 28-36. [CrossRef]

22. Park, S.; Lee, S.; Kim, W.-S. Polymorphic Crystallization of Sulfamerazine in Taylor Vortex Flow: Polymorphic Nucleation and Phase Transformation. Cryst. Growth Des. 2015, 15, 3617-3627. [CrossRef]

23. Nguyen, A.-T.; Kim, W.-S. Influence of Feeding Mode on Cooling Crystallization of L-Lysine in Couette-Taylor Crystallizer. Korean J. Chem. Eng. 2017, 34, 2002-2010. [CrossRef]

24. Nguyen, A.-T.; Kim, W.-S. Effect of Sinusoidal Taylor Vortex Flow on Cooling Crystallization of L-Lysine. Korean J. Chem. Eng. 2017, 34, 1896-1904. [CrossRef]

25. Park, S.; Kim, W.-S. Influence of Fluid Motions on Polymorphic Crystallization of 1-Histidine: Taylor Vortex Flow and Turbulent Eddy Flow. Cryst. Growth Des. 2018, 18, 710-722. [CrossRef]

26. Batchelor, G.K. Note on a Class of Solutions of the Navier-Stokes Equations Representing Steady Rotationally Symmetric Flow. $Q$. J. Mech. Appl. Math. 1951, 4, 29-41. [CrossRef]

27. Bödewadt, U.T. Die Drehströmung über Festem Grunde. Z. Angew. Math. Mech. 1940, 20, 241-253. [CrossRef]

28. VoKármán, T.V.T. Über Laminare und Turbulente Reibung. Z. Angew. Math. Mech. 1921, 1, 233-252. [CrossRef]

29. Daily, J.W.; Nece, R.E. Chamber Dimension Effects on Induced Flow and Frictional Resistance of Enclosed Rotating Disks. J. Basic Eng. 1960, 82, 217-230. [CrossRef]

30. Cros, A.; Ali, R.; Le Gal, P.; Thomas, P.J.; Schouveiler, L.; Carpenter, P.W.; Chauve, M.P. Effects of Wall Compliance on the Laminar-Turbulent Transition of Torsional Couette Flow. J. Fluid Mech. 2003, 481, 177-186. [CrossRef]

31. Cros, A.; Floriani, E.; Le Gal, P.; Lima, R. Transition to Turbulence of the Batchelor Flow in a Rotor/Stator Device. Eur. J. Mech. B Fluids 2005, 24, 409-424. [CrossRef]

32. Visscher, F.; van der Schaaf, J.; de Croon, M.H.J.M.; Schouten, J.C. Liquid-liquid mass transfer in a rotor-stator spinning disc reactor. Chem. Eng. J. 2012, 185-186, 267-273. [CrossRef]

33. Meeuwse, M.; Lempers, S.; van der Schaaf, J.; Schouten, J.C. Liquid-solid mass transfer and reaction in a rotor-stator spinning disc reactor. Ind. Eng. Chem. Res. 2010, 49, 10751-10757. [CrossRef] 